\title{
Value-Added Roles of Medical Students During COVID-19 Pandemic: Assessment of Medical Students' Perception and Willingness in Sri Lanka
}

Nuwan Wickramasinghe ( $\nabla$ nuwick74@yahoo.com )

Faculty of Medicine and Allied Sciences, Rajarata University of Sri Lanka

Shamalee Jayarathne

Faculty of Medicine and Allied Sciences, Rajarata University of Sri Lanka

Senaka Pilapitiya

Faculty of Medicine and Allied Sciences, Rajarata University of Sri Lanka

\section{Research Article}

Keywords: Value-added roles, COVID-19, Medical education, Heath sector response

Posted Date: December 14th, 2020

DOI: https://doi.org/10.21203/rs.3.rs-117399/v1

License: (c) (i) This work is licensed under a Creative Commons Attribution 4.0 International License.

Read Full License 


\section{Abstract}

\section{Background}

COVID-19 pandemic is an opportune time to identify the value-added roles of medical students to utilize the services of this potential workforce effectively in the health-care system. Hence, this study assessed medical students' perception and willingness to assist in COVID-19 health sector preparedness and response via value-added roles in Sri Lanka.

\section{Methods}

A cross-sectional online survey was conducted among all medical students studying in six batches of the Faculty of Medicine and Allied Sciences (FMAS), Rajarata University of Sri Lanka (RUSL). A Google form prepared in English with statements about individual perception of medical students' role and their willingness to assist in the COVID-19 health sector response via value-added roles was used to collect data.

Results

Out of $856(79.6 \%)$ study participants, the majority was females $(n=601,70.2 \%)$. The majority $(n=804$, 93.9\%) reported that they have a responsibility to contribute to the COVID-19 health sector response in the country. There was a statistically significant difference in medical students' perceived level of clinical knowledge and clinical skills to assist in COVID-19 health sector response with advancing academic year $(\mathrm{p}<0.001)$. The commonly identified value-added roles were developing $(\mathrm{n}=770,89.9 \%)$ and disseminating $(n=744,86.9 \%)$ health education messages, and field contact tracing activities $(n=653,76.3 \%)$. Other value-added roles were assisting the curative health sector in COVID-19 patient management $(n=380$, $44.4 \%)$ and other non-COVID-19 patient management $(n=463,54.1 \%)$.

\section{Conclusions}

Medical students are mostly willing to be engaged in the preventive health sector value-added roles and to a lesser extent in the curative health sector value-added roles during the COVID-19 outbreak. However, the medical educators need to clearly define the value-added roles and provide adequate training and supervision for medical students, from the first year to the final year, to combine learning with meaningful contributions to patient care and health-care system during the COVID-19 pandemic.

\section{Background}

Due to the Corona Virus Disease-19 (COVID-19) pandemic, the world is experiencing one of the greatest threats in the global education system at the moment, which could potentially lead to a gigantic educational crisis. Across the globe, many governments have temporarily closed educational institutions, including medical faculties and colleges in an attempt to contain the spread of the COVID-19 pandemic [1-6]. 
Against the ever-increasing COVID-19 caseload, the health-care sectors of countries across the globe are faced with an inevitable risk of medical demand outpacing the health-care capacity $[1,7]$. Thus, countryspecific health sector preparedness and response plans to COVID-19 need to be proactively developed by effectively utilizing the limited resources [7-8]. With regard to human resources in COVID-19 health sector preparedness and response, medical students could be considered as a potential group that could be effectively utilized. Evidence suggests that deployment of the enthusiastic medical student workforce will supplement and expedite the process of existing health-care interventions during the COVID-19 pandemic [9].

However, there is no universal consensus on the appropriate roles for medical students during a pandemic; thus, their involvement in health sector response in countries across the world is different $[4,5,10,11]$. Literature highlights a paradoxical dual role of medical students during the COVID-19 pandemic [12]. At one end, as the future health-care workforce, they potentially form part of a health-care system's response to public health emergencies, while on the other end, they are considered as nonessential in clinical delivery [12].

Given the novelty of this COVID-19 pandemic, it is evident that the medical schools are ill prepared to respond promptly and comprehensively to a pandemic of this proportion. Hence, it is timely and vital to identify how medical students can contribute to the health sector preparedness and response, which includes both preventive sector and curative sector. It is an opportune time for the medical schools to define competency level of each year of medical students to prepare and respond to global health emergencies. The competency level definition and identification process needs to incorporate the inputs from both medical students and academia, which will ultimately facilitate in developing a strategic plan in responding to future similar conditions to assist the health-care sector.

This COVID-19 pandemic has provided with an opportunity to consider immersion of medical students in to the health-care system in the country. The 'communities of practice' theory of medical education highlights the importance of learning-by-participation rather than learning-by-acquisition, where the mode of learning is authentic work [13]. Furthermore, it is suggested that medical schools should offer clinical opportunities to students that would benefit patient care and potentially help to prevent workforce shortages during the COVID-19 pandemic [4]. Hence, COVID-19 pandemic would be a great opportunity to medical students to learn and develop their management skills, personal skills and to appreciate the importance of the multidisciplinary approach in health-care delivery.

Against this background, we believe that the concept of 'value-added medical education' needs to be promoted by global medical educators in the view of transforming medical students' roles in to valueadded roles, which are defined as "Roles that are experiential and authentic, and have the potential for a positive impact on outcomes related to patients, populations, costs of care, or other processes within the health-care system, and enhance student knowledge, attitudes, and skills in the clinical science" [14-16].

Prior to considering the ways of immersing medical students in to the health-care systems, it is important to assess the willingness of medical students to contribute to the health sector response to COVID-19 
pandemic. However, global evidence exploring this aspect is scarce. Despite the lack of evidence generated by original research, opinion-based evidence suggests that medical students from varying clinical contexts have expressed their willingness to contribute to the health-care systems during the COVID-19 pandemic $[12,17]$.

With regard to the Sri Lankan scenario, the first confirmed case of COVID-19, who was a Chinese national, was reported on 27 January 2020 and the first confirmed local case was reported on 11 March 2020 [18]. The Sri Lankan government has taken both suppression and mitigation measures at the onset of the COVID-19 outbreak in Sri Lanka in a cascading manner, which had been reasonably effective thus far in prevention of wide spread community transmission $[18,19]$.

At the moment, Sri Lankan health sector is managing the disease burden of COVID-19 with available human as well as physical resources, largely owing to the fact that still there is no wide spread community transmission attributed to strict suppression and mitigation measures [19]. If the health sector is not fully prepared with proactive measures including effective utilization of any available human resources, the country would find it extremely difficult with inevitable subsequent waves of the COVID-19 outbreak.

In this background, it is important to identify the perceptions and willingness of medical students to contribute to the health sector COVID-19 preparedness and response via value-added roles in order to utilize the services of this potential workforce effectively in the future. Hence, the aim of the present study was to assess the medical students' perception and willingness to assist in COVID-19 health sector preparedness and response via value-added roles in a state sector medical faculty in Sri Lanka.

\section{Methods}

\section{Study design and setting}

We carried out a cross-sectional online survey among the medical students at the Faculty of Medicine and Allied Sciences (FMAS), Rajarata University of Sri Lanka (RUSL) for a period of two weeks in early June, 2020.

At present, six batches of medical students are studying in the FMAS, RUSL. The FMAS is one of the eleven state sector medical faculties in Sri Lanka. The academic programme is conducted (in English medium) over a period of five years and it consists of four main phases; Foundation for medical studies, Pre-clinical, Para-clinical and Clinical phases. The foundation phase is designed to make students familiar with the university setting, to improve their life skills and learning skills, and to make them aware of the basic aspects of medical ethics and professionalism. During the pre-clinical phase, students will acquire basic knowledge and skills in relation to normal structure, functions of the human body and the basis for dysfunction. Students obtain theoretical, practical and management of abnormal structure and function of the human body during their para-clinical phase. A comprehensive clinical training starts from the third year of the academic programme. 


\section{Participants}

At present, there are 1,075 medical students studying in all six batches in the FMAS, RUSL. Of them, the majority are female students $(n=721,67.1 \%)$. We invited all medical students to participate in the study and we requested those who consented to complete the online survey.

\section{Measures}

We prepared a Google form in English, comprising of ten statements about individual medical students' perception and willingness to contribute to the COVID-19 health sector preparedness and response via value-added roles, for data collection. A multidisciplinary panel of experts representing the fields of Medical Education, Public Health and Clinical Medicine prepared the questionnaire items. Participants responded to each questionnaire item (statement) on a five-point Likert scale to indicate their agreeableness.

We uploaded the online survey to the Moodle, which is the Learning Management System of the faculty, in order to provide an opportunity of easy accessibility by the remote participants. Enrolment in the study was completely voluntary and we attached an online invitation to participate the study to the Google form with details of the study and the basic sections of the questionnaire. We obtained the online informed consent prior to completion of the questionnaire. We did not collect any personally identifiable information and we preserved the anonymity.

\section{Data analysis}

We performed data analysis using IBM SPSS Statistics for Macintosh, Version 25.0. We used descriptive statistics with frequency distributions and graphs to present data. Participants' responses on the fivepoint Likert scale were dichotomized as 'Agree' (by combining the responses 'agree' and 'strongly agree') and 'Disagree' (by combining the responses 'neither agree nor disagree', 'disagree' and 'strongly disagree'). We compared academic year-wise responses and Chi-squared test was used to assess the statistical significance of the differences.

\section{Results}

\section{Sample characteristics}

A total of 856 medical students completed the online questionnaire and the response rate was $79.6 \%$. The majority were female medical students ( $n=601,70.2 \%)$. The academic year-wise breakdown of the sample is given in Figure 1 and fourth year medical students represented the highest percentage $(n=180$, $21.0 \%)$.

Table 1 summarizes the male and female medical students of the sample by the academic year.

Table 1 Sample of medical students by sex and by the academic year 


\begin{tabular}{|c|c|c|c|c|c|c|}
\hline \multirow[t]{2}{*}{ Academic year } & & \multicolumn{2}{|c|}{ Female } & \multicolumn{2}{|c|}{ Male } & \multirow[t]{2}{*}{ Total } \\
\hline & & $\mathbf{n}$ & $\%$ & $\mathbf{n}$ & $\%$ & \\
\hline Foundation phase & Introductory year & 111 & 71.6 & 44 & 28.4 & 155 \\
\hline \multirow[t]{2}{*}{ Pre-clinical phase } & First year & 114 & 77.5 & 33 & 22.5 & 147 \\
\hline & Second year & 66 & 65.4 & 35 & 34.6 & 101 \\
\hline Para-clinical phase & Third year & 106 & 70.2 & 45 & 29.8 & 151 \\
\hline Para-clinical + Clinical phase & Fourth year & 113 & 62.8 & 67 & 37.2 & 180 \\
\hline \multirow[t]{2}{*}{ Clinical phase } & Final year & 91 & 74.6 & 31 & 25.4 & 122 \\
\hline & Total & 601 & 70.2 & 255 & 29.8 & 856 \\
\hline
\end{tabular}

\section{Overall responses of the sample of medical students}

The percentage agreements for each of the ten statements by the sample of medical students are given in Figure 2 . The majority $(93.9 \%, n=804)$ reported that they have a responsibility to contribute to the COVID-19 health sector response in the country.

In relation to the perceived competencies, $46.3 \%(n=396)$ believed that they possess adequate medical knowledge to contribute to the COVID-19 health sector response, while only $23.1 \%(n=198)$ believed they have adequate clinical skills to contribute effectively.

Regarding the potential value-added roles, the majority reported that they could help in the preventive health sector activities during the COVID-19 outbreak. Most of the students believed that they could assist/participate in developing health education messages $(n=770,89.9 \%)$, disseminating health messages $(n=744,86.9 \%)$ and field contact tracing activities of the COVID-19 patients $(n=653,76.3 \%)$.

In comparison to the responses on value-added roles in preventive health sector activities, a lower percentage of medical students reported they could assist the curative health sector activities during the COVID-19 outbreak. Only 44.4\% ( $n=380)$ medical students believed that they could assist in COVID-19 patient management in the hospitals and $54.1 \%(n=463)$ believed that they could assist the curative health sector in managing other patients in hospitals, as health-care staff is busy managing the COVID19 patients.

Overall, 32.0\% ( $n=274)$ believed that the government and/or the health sector is/are effectively utilizing the potential of medical students in the health sector response during the COVID-19 outbreak. Compared to that response, a higher percentage of medical students $(n=380,44.4 \%)$ believed that medical students, as student groups, are actively involved in health activities related to COVID-19. 
The percentage agreements for each of the ten statements by the sample of medical students according to the academic year are summarized in Table 2 and Figure 3.

Irrespective of the academic year of study, almost all medical students reported that they have a responsibility to contribute to the health services of the country during the COVID-19 outbreak. The responses of medical students' by the academic year did not reveal statistically significant difference (Chi $(5)=2.9, p=0.716)$ and the responses varied from $91.6 \%$ to $95.2 \%$.

It is noteworthy to observe that with advancing academic year, the medical students' perceived level of clinical knowledge and clinical skills to assist in COVID-19 health sector response increased. The percentages increased from $18.1 \%$ in the introductory year to $74.6 \%$ in the fifth year (Chi (5) $=158.4$, $p<0.001)$ regarding the clinical knowledge. More striking difference was observed from $3.2 \%$ in the introductory year to $65.6 \%$ in the fifth year $($ Chi $(5)=239.1, p<0.001)$.

Table 2 Medical students' responses to each statement by the academic year 


\begin{tabular}{|c|c|c|c|c|c|c|c|}
\hline Statement & $\begin{array}{l}\text { Introductory } \\
\text { year } \\
\text { n (\%) }\end{array}$ & $\begin{array}{l}\text { First } \\
\text { year } \\
n(\%)\end{array}$ & $\begin{array}{l}\text { Second } \\
\text { year } \\
\mathrm{n}(\%)\end{array}$ & $\begin{array}{l}\text { Third } \\
\text { year } \\
\mathrm{n}(\%)\end{array}$ & $\begin{array}{l}\text { Fourth } \\
\text { year } \\
\text { n (\%) }\end{array}$ & $\begin{array}{l}\text { Fifth } \\
\text { Year } \\
\text { n (\%) }\end{array}$ & Significance \\
\hline 1 & $\begin{array}{l}142, \\
91.6 \%\end{array}$ & $\begin{array}{l}140 \\
95.2 \%\end{array}$ & $\begin{array}{l}96, \\
95.1 \%\end{array}$ & $\begin{array}{l}140 \\
92.7 \%\end{array}$ & $\begin{array}{l}171, \\
95.0 \%\end{array}$ & $\begin{array}{l}115 \\
94.3 \%\end{array}$ & $\begin{array}{l}\text { Chi=2.9, } \\
\text { df=5, } \\
p=0.716\end{array}$ \\
\hline 2 & $\begin{array}{l}28, \\
18.1 \%\end{array}$ & $\begin{array}{l}42, \\
28.6 \%\end{array}$ & $\begin{array}{l}43, \\
42.6 \%\end{array}$ & $\begin{array}{l}62, \\
41.1 \%\end{array}$ & $\begin{array}{l}130 \\
72.2 \%\end{array}$ & $\begin{array}{l}91, \\
74.6 \%\end{array}$ & $\begin{array}{l}\text { Chi=158.4, } \\
d f=5, \\
p<0.001\end{array}$ \\
\hline 3 & $\begin{array}{l}5, \\
3.2 \%\end{array}$ & $\begin{array}{l}12 \\
8.2 \%\end{array}$ & $\begin{array}{l}7, \\
6.9 \%\end{array}$ & $\begin{array}{l}18, \\
11.9 \%\end{array}$ & $\begin{array}{l}76, \\
42.2 \%\end{array}$ & $\begin{array}{l}80, \\
65.6 \%\end{array}$ & $\begin{array}{l}\text { Chi=239.1, } \\
d f=5, \\
p<0.001\end{array}$ \\
\hline 4 & $\begin{array}{l}43 \\
27.7 \%\end{array}$ & $\begin{array}{l}49, \\
33.3 \%\end{array}$ & $\begin{array}{l}34, \\
33.7 \%\end{array}$ & $\begin{array}{l}58, \\
38.4 \%\end{array}$ & $\begin{array}{l}101, \\
56.1 \%\end{array}$ & $\begin{array}{l}95, \\
77.9 \%\end{array}$ & $\begin{array}{l}\text { Chi=96.9, } \\
d f=5, \\
p<0.001\end{array}$ \\
\hline 5 & $\begin{array}{l}52, \\
33.6 \%\end{array}$ & $\begin{array}{l}65 \\
44.2 \%\end{array}$ & $\begin{array}{l}43 \\
42.6 \%\end{array}$ & $\begin{array}{l}76, \\
50.3 \%\end{array}$ & $\begin{array}{l}126 \\
70 \%\end{array}$ & $\begin{array}{l}101, \\
82.1 \%\end{array}$ & $\begin{array}{l}\text { Chi=97.2, } \\
d f=5, \\
p<0.001\end{array}$ \\
\hline 6 & $\begin{array}{l}79, \\
50.9 \%\end{array}$ & $\begin{array}{l}103 \\
70.1 \%\end{array}$ & $\begin{array}{l}74, \\
73.3 \%\end{array}$ & $\begin{array}{l}133 \\
88.1 \%\end{array}$ & $\begin{array}{l}153 \\
85 \%\end{array}$ & $\begin{array}{l}111 \\
90.9 \%\end{array}$ & $\begin{array}{l}\text { Chi=92.3, } \\
d f=5, \\
p<0.001\end{array}$ \\
\hline 7 & $\begin{array}{l}120 \\
77.4 \%\end{array}$ & $\begin{array}{l}132, \\
89.8 \%\end{array}$ & $\begin{array}{l}95, \\
94.1 \%\end{array}$ & $\begin{array}{l}146, \\
96.7 \%\end{array}$ & $\begin{array}{l}164, \\
91.1 \%\end{array}$ & $\begin{array}{l}113 \\
92.6 \%\end{array}$ & $\begin{array}{l}\text { Chi=37.6, } \\
d f=5, \\
p<0.001\end{array}$ \\
\hline 8 & $\begin{array}{l}112, \\
72.3 \%\end{array}$ & $\begin{array}{l}126 \\
85.7 \%\end{array}$ & $\begin{array}{l}90, \\
89.1 \%\end{array}$ & $\begin{array}{l}141 \\
93.4 \%\end{array}$ & $\begin{array}{l}158, \\
87.8 \%\end{array}$ & $\begin{array}{l}117 \\
95.9 \%\end{array}$ & $\begin{array}{l}\text { Chi=44.2, } \\
d f=5, \\
p<0.001\end{array}$ \\
\hline 9 & $\begin{array}{l}57, \\
36.8 \%\end{array}$ & $\begin{array}{l}61, \\
41.5 \%\end{array}$ & $\begin{array}{l}36, \\
35.6 \%\end{array}$ & $\begin{array}{l}51, \\
33.8 \%\end{array}$ & $\begin{array}{l}41, \\
22.8 \%\end{array}$ & $\begin{array}{l}28 \\
22.9 \%\end{array}$ & $\begin{array}{l}\text { Chi=20.2, } \\
d f=5, \\
p=0.001\end{array}$ \\
\hline 10 & $\begin{array}{l}88, \\
56.8 \%\end{array}$ & $\begin{array}{l}88, \\
59.9 \%\end{array}$ & $\begin{array}{l}50, \\
49.5 \%\end{array}$ & $\begin{array}{l}73, \\
48.3 \%\end{array}$ & $\begin{array}{l}51, \\
28.3 \%\end{array}$ & $\begin{array}{l}30, \\
24.6 \%\end{array}$ & $\begin{array}{l}\text { Chi=64.1, } \\
d f=5, \\
p<0.001\end{array}$ \\
\hline
\end{tabular}


In relation to the perceived ability to contribute to the health sector response, an increasing trend was observed with advancing academic years on perceived ability to contribute to the curative health sector activities. However, a similar increasing trend was not observed in relation to the perceived ability to contribute to the preventive health sector activities.

On the other hand, with advancing academic years lower number of medical students believed that the government and/or the health sector is/are effectively utilizing the potential of medical students in the health sector response during the COVID-19 outbreak year (Chi $(5)=20.2, p=0.001)$. Similarly, with advancing academic years lower number of medical students believed that medical students, as student groups, are actively involved in health activities related to COVID-19 (Chi (5) $=64.1, p<0.001)$.

\section{Discussion}

Global medical education has faced numerous challenges in continuing traditional teaching-learning activities due to COVID-19 pandemic. Hence, it is an opportune time to identify value-added roles of medical students to benefit students, patients and also the health systems across the globe. Against this backdrop, the present study aimed to assess the medical students' perception of their role and willingness to assist in COVID-19 health sector preparedness and response.

Accordingly, a cross-sectional study was conducted via Moodle platform, considering the easy accessibility to the study participants. In addition, experts representing the fields of Medical Education, Public Health and Clinical Medicine prepared the study questionnaire, specifically focusing on simplicity, while including important value-added roles. Consequently, the response rate of the present study was approximately $80 \%$, which is a strength of the study. The majority of the sample was female students and the proportion was similar to that in the student population, FMAS, RUSL.

It is noteworthy to observe that almost all, i.e. except eight $(0.9 \%)$ medical students, reported that they have a responsibility to contribute to the COVID-19 health sector response in the country, which indirectly highlight their academic and moral obligation. Further, it is important to note that irrespective of the academic year, all medical students were having a similar opinion. In spite of their willingness to be involved in the COVID-19 health sector response, only one third of students believed that the government and/or the health sector is/are effectively utilizing the potential of medical students in the health sector response during the COVID-19 outbreak. In the context of identifying the readiness to engage in valueadded roles, this evidence lays a positive platform.

Approximately, more than two times the students perceived that they have adequate clinical knowledge in comparison to adequate clinical skills to contribute to the COVID-19 health sector response. Furthermore, with advancing academic year, the medical students' perceived level of clinical knowledge and clinical skills to assist in COVID-19 health sector response increased. Especially, three quarters and two thirds of students in the fifth year believed that they have adequate clinical knowledge and clinical skills respectively in this regard. At the same time, it is important to appreciate the very low level of perceived adequacy of clinical knowledge and skills among the students in the foundation and pre-clinical phases. 
As given above, since students in the foundation and pre-clinical phases have minimal exposure to clinical appointments, this observation is explicable. This finding highlights that students can be better integrated to health-care teams by recognising meaningful contribution from first year to final year. Thus, medical education needs to identify value-added roles for medical students across different academic training in order to combine learning with meaningful contributions to patient care and health sector.

In relation to the potential value-added roles, the majority of medical students have reported their willingness mainly in relation to the preventive sector activities irrespective of their academic year. Given that these value-added roles, which include developing and disseminating health messages and field contact tracing, need relatively minimal training and supervision, health-care teams could easily incorporate medical students in such activities to reinforce the existing health-care workforce. The importance of having opportunities to incorporate creativity in medical educators is widely recognised [20-22]. Hence, the involvement of the creative and energetic younger health workforce could be a fruitful investment in this regard.

During the to COVID-19 pandemic, clinical teaching and training has been mainly affected [4,6,23]; thus, introduction of value-added activities in the clinical settings would be of greater significance and also would yield reciprocal benefits. As per the communities of practice theory, this allows learning-byparticipation rather than learning-by-acquisition for medical students. However, considering the competency gap in their perceived level of relevant clinical knowledge and skills, such activities need to be carried with meticulous supervision under safe working environments. In light of the findings of the present study, providing more opportunities and training in managing other patients in hospitals for the final year medical students, as health-care staff is busy managing the COVID-19 patients, would be beneficial to manage the work overload in the clinical health-care settings.

\section{Conclusions}

Medical students believe that they have a responsibility to contribute to the COVID-19 health sector response in the country. They are mostly willing to be engaged in the preventive health sector value-added roles and to a lesser extent in the curative health sector value-added roles during the COVID-19 outbreak. However, the medical educators need to clearly define the value-added roles and provide adequate training and supervision for medical students, from the first year to the final year, to combine learning with meaningful contributions to patient care and health-care system during the COVID-19 pandemic.

\section{Abbreviations}

COVID-19: Corona Virus Disease 2019; FMAS: Faculty of Medicine and Allied Sciences; RUSL: Rajarata University of Sri Lanka

\section{Declarations}


Ethics approval and consent to participate

Ethical clearance to conduct the study was obtained from the Ethics Review Committee of the Faculty of Medicine and Allied Sciences, Rajarata University of Sri Lanka (Reference no: ERC/2020/40). Informed consent from all the participants were obtained prior to online data collection.

Consent for publication

Not applicable.

Availability of data and material

The dataset used and analysed during the present study is available from the corresponding author on reasonable request.

Competing interests

The authors declare that they have no competing interests.

Funding

This research received no specific grant from any funding agency in the public, commercial or not-forprofit sectors.

Authors' contributions

NDW conceived the study concept. NDW, SWJ and SDP were involved designed the study. NDW and SWJ collected data. NDW analysed and interpreted data. SWJ and SDP made substantial contribution to data analysis and interpretation. NDW prepared the manuscript. SWJ and SDP made substantial contribution to revise the manuscript. All authors read and approved the final manuscript.

Acknowledgements

The authors wish to thank all the study participants.

Authors' Information

${ }^{1}$ Department of Community Medicine, Faculty of Medicine and Allied Sciences, Rajarata University of Sri Lanka, Saliyapura, (50008), Sri Lanka; ${ }^{2}$ Medical Education Unit, Faculty of Medicine and Allied Sciences, Rajarata University of Sri Lanka, Saliyapura, (50008), Sri Lanka; ${ }^{3}$ Department of Medicine, Faculty of Medicine and Allied Sciences, Rajarata University of Sri Lanka, Saliyapura, (50008), Sri Lanka.

\section{References}


[1] Bank I, Wijnen-Meijer M. 2020. Why should medical students (not) be recruited to care for patients with COVID-19?. BMC Med Educ. 20(1):1-5.

[2] Yu NZ, Li ZJ, Chong YM, Xu Y, Fan JP, Yang Y, Teng Y, Zhang YW, Zhang WC, Zhang MZ, Huang JZ. 2020. Chinese medical students' interest in COVID-19 pandemic. World J Virol. 9(3):38.

[3] Armstrong A, Jeevaratnam J, Murphy G, Pasha M, Tough A, Conway-Jones R, Mifsud RW, Tucker S. 2020. A plastic surgery service response to COVID-19 in one of the largest teaching hospitals in Europe. JPRAS. 73(6):1174-1205.

[4] Miller DG, Pierson L, Doernberg S. 2020. The role of medical students during the COVID-19 pandemic. Ann Intern Med.

[5] Mahase E. 2020. Covid-19: Portugal closes all medical schools after 31 cases confirmed in the country. BMJ. 368:M986.

[6] Rose S. 2020. Medical student education in the time of COVID-19. JAMA. 323(21):2131-2132.

[7] Walker P, Whittaker C, Watson O, Baguelin M, Ainslie K, Bhatia S, Bhatt S, Boonyasiri A, Boyd O, Cattarino L, et al. 2020. Report 12: The global impact of COVID-19 and strategies for mitigation and suppression.

[8] World Health Organization. 2020. Responding to community spread of COVID-19: interim guidance.

[9] Hasan MT. 2020. Considering voluntary contribution of medical students to tackle COVID-19 crisis at hospitals in Bangladesh \& similar settings. PsyArXiv.

[10] Stokes DC. 2020. Senior medical students in the COVID-19 response: an opportunity to be proactive. AEM. 27(4):343-345.

[11] Harvey A. 2020. Covid-19: medical students and FY1 doctors to be given early registration to help combat covid-19. BMJ. 368:m1268.

[12] Baker DM, Bhatia S, Brown S, Cambridge W, Kamarajah SK, McLean KA, Brindl N, Lapolla P, PérezAjates S, Raubenheimer K, et al. 2020. Medical student involvement in the COVID-19 response. Lancet. 395(10232):1254.

[13] Morris CS. 2018. On communities of practice in medical education. Acad. Med. 93(12):1752.

[14] Gonzalo JD, Dekhtyar M, Hawkins RE, Wolpaw DR. 2017a. How can medical students add value? Identifying roles, barriers, and strategies to advance the value of undergraduate medical education to patient care and the health system. Acad. Med. 92(9):1294-1301.

[15] Gonzalo JD, Dekhtyar M, Starr SR, Borkan J, Brunett P, Fancher T, Green J, Grethlein SJ, Lai C, Lawson L, et al. 2017b. Health systems science curricula in undergraduate medical education: identifying and 
defining a potential curricular framework. Acad. Med. 92(1):123-131

[16] Gonzalo JD, Graaf D, Johannes B, Blatt B, Wolpaw DR. 2017c. Adding value to the health care system: Identifying value-added systems roles for medical students. Am. J. Med. 32(3):261-270.

[17] Thomson E, Lovegrove S. 2020. 'Let us Help'-Why senior medical students are the next step in battling the COVID-19 Pandemic. Int. J. Clin. Pract. 74:e13516.

[18] Hewage S, Wickramasinghe N, Jayakody S, Samaranayake D, Prathapan S, Arambepola C. 2020. Social distancing and its impact on flattening the COVID-19 curve in Sri Lanka. JCCPSL. 26(1):65-70.

[19] Ediriweera DS, de Silva NR, Malavige NG, de Silva HJ. 2020. An epidemiological model to aid decision-making for COVID-19 control in Sri Lanka. medRxiv.

[20] Green MJ, Myers K, Watson K, Czerwiec MK, Shapiro D, Draus S. Creativity in medical education: the value of having medical students make stuff. Journal of Medical Humanities. 2016;37(4):475-83.

[21] Kim Y, Lee YH. 2020. Creativity in medical education: concepts related to creative capacity. Yeungnam Univ J Med. 37(2):79.

[22] Shaywitz DA, Ausiello DA. 2004. Preserving creativity in medicine. PLoS Med. 1(3):e34.

[23] Roll R, Chiu M, Huang C. 2020. Answering the Call to Action: COVID-19 Curriculum Design by Students for Students. Acad. Med.

\section{Figures}




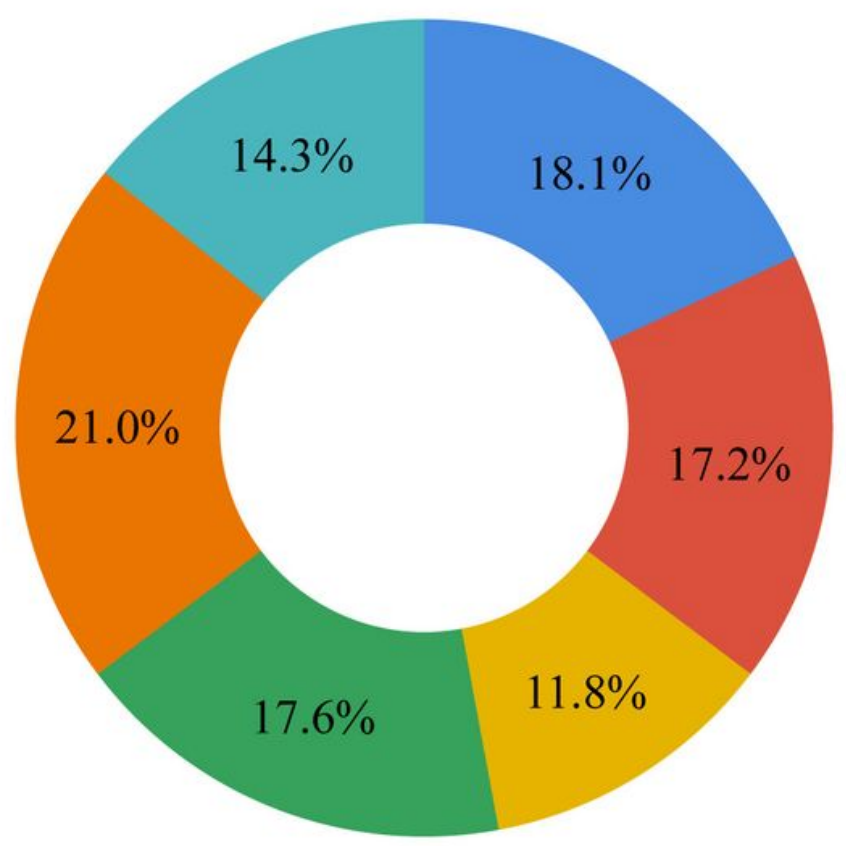

Introductory year

First year

Second year

Third year

Fourth year

Final year

Figure 1

Sample of medical students by the academic year $(n=856)$

10. I think the medical undergraduates as student groups, are actively involved in health activities related to COVID-19.

9. I think the government and/or the health sector is effectively utilizing the potential of medical undergraduates in health sector response during the

8. As a medical undergraduate, I think I can help the health sector in disseminating health messages on COVID-19 prevention and control.

7. As a medical undergraduate, I think I can help the preventive health sector in developing health education messages for COVID-19 prevention and control.

6. As a medical undergraduate, I think I can help the preventive health sector in contact tracing activities of the COVID-19 patients in the field.

5. As a medical undergraduate, I think I can help the curative health sector in managing other patients in hospitals, as health care staff is busy managing the

4. As a medical undergraduate, I think I can help the curative health sector in COVID-19 patient management in hospitals.

3. As a medical undergraduate, I think I have adequate clinical skills to contribute to the health services of the country during the COVID-19 outbreak.

2. As a medical undergraduate, I think I have adequate medical knowledge to contribute to the health services of the country during the COVID-19 outbreak.

1. As a medical undergraduate, I think I have a responsibility to contribute to the health services of the country during the COVID-19 outbreak.

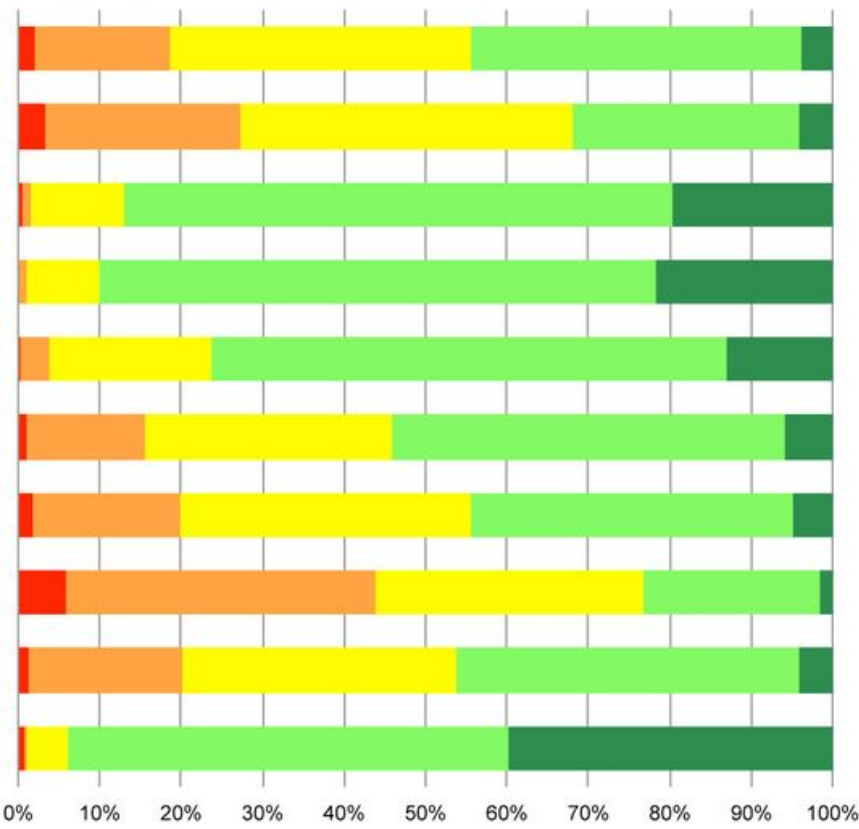

= Strongly disagree $=$ Disagree $\quad$ Neither agree nor disagree $=$ Agree $\quad$ Strongly agree

Figure 2

Response to each statement by medical students $(n=856)$ 


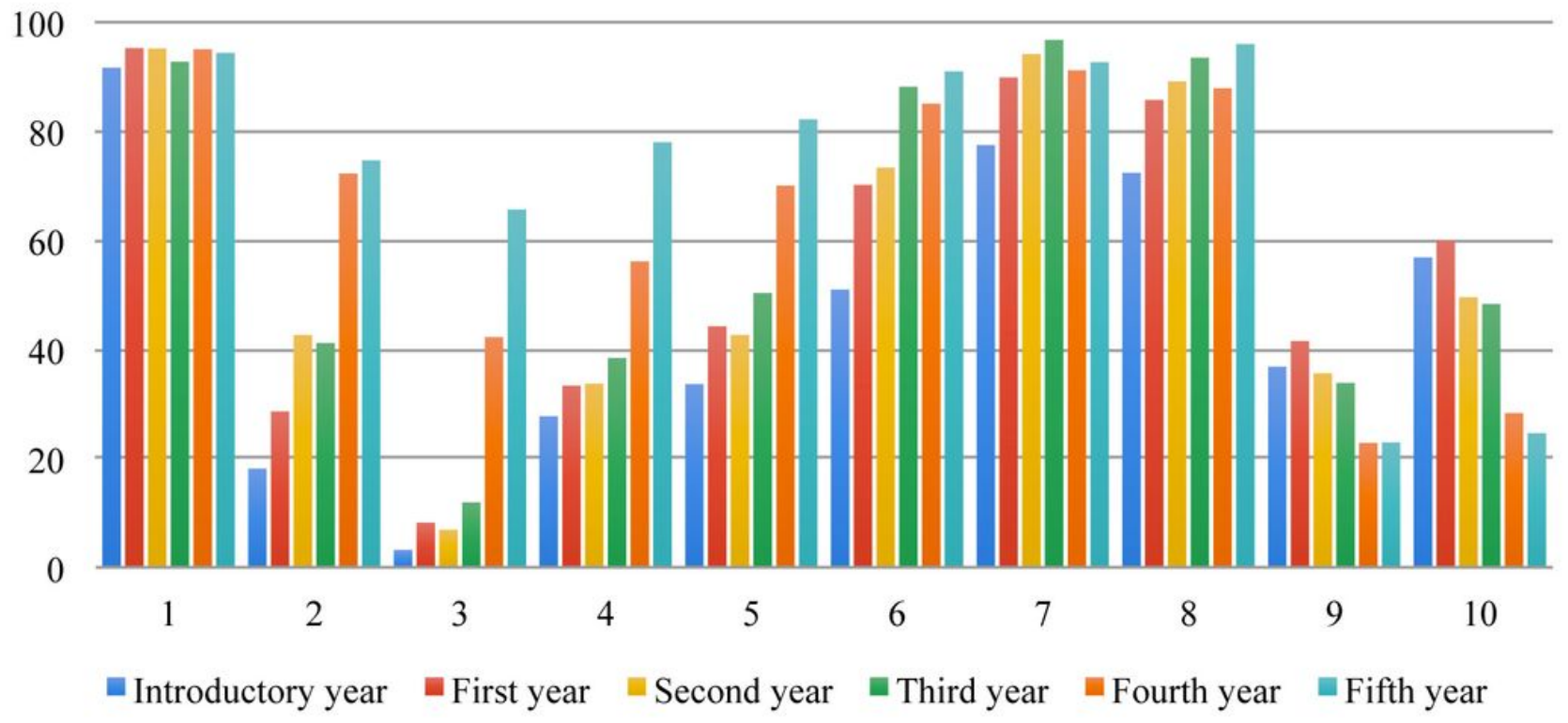

Figure 3

Medical students' responses to each statement by the academic year 